\title{
Points, patches, and regions: scaling soil biogeochemical patterns in an urbanized arid ecosystem
}

\author{
G. DARREL JENERETTE*1, JIANGUO WU ${ }^{*} \dagger$, NANCY B. GRIMM ${ }^{*} \dagger$ and DIANE HOPE $\dagger$ \\ *School of Life Sciences, Arizona State University, Tempe, AZ 85287, USA, †International Institute for Sustainability, \\ Arizona State University, Tempe, AZ 85287, USA
}

\begin{abstract}
Cities are rapidly growing throughout the world and are altering biologic processes in many regions, with global consequences. Urbanization in the Phoenix, USA metropolitan region has dramatically altered regional ecosystem patterns, but little is known about how these changes have influenced soil organic matter, total nitrogen, and the distribution of nitrogen stable isotopes. Because urban development is a phenomenon occurring at multiple scales, ecological consequences of urbanization will likely differ between individual patches and the entire metropolitan region. To investigate such changes we conducted spatially explicit surveys including three dominant land-use types in this region: native desert, agriculture, and mesic residential. These data were combined for analysis with previously collected samples from a synoptic regional survey. A landscape scaling approach was implemented to compare the dependence of soil variability on the sampled extent and the uncertainty associated with scaling from points to patches, landuse types, and the Phoenix metropolitan region. The multiple-scale analysis of soil properties showed that variation in total soil nitrogen, soil organic matter, and $\delta^{5} \mathrm{~N}$ content of soils differed between patch and regional scales. The majority of variation in the urbanized patch types was exhibited between patches while for the native desert the majority of variation was observed within individual patches. These differences show the impact of urbanization on the scaling relations of ecosystem components. Overall, urbanization in this region appears to have increased soil organic matter by $44 \%$, total nitrogen by $48 \%$, and has elevated $\delta^{15} \mathrm{~N}$ by $21 \%$.
\end{abstract}

Keywords: heterogeneity, land-use change, Monte Carlo, nitrogen, organic matter, Phoenix, scaling, stable isotopes, urbanization, uncertainty

Received 5 May 2005; revised version received 2 December 2005; accepted 12 January 2006

\section{Introduction}

Urbanization exerts a strong effect on ecosystem patterns and processes from local to regional scales (Grimm et al., 2000; Pickett et al., 2001) and is an important component of global land-use change (Vitousek, 1994; United Nations Centre for Human Settlements, 2001). However, the consequences of urbanization for soil total nitrogen (TN) and organic matter (OM) pools are poorly understood (Craul, 1985; Beyer et al., 1995; Howard et al., 1995; Schleuss et al., 1998; Pouyat et al., 2002). Because soils constitute the largest reservoir of terres-

Correspondence: G. Darrel Jenerette, e-mail: jenerette@gmail.com

${ }^{1}$ Present address: Department of Ecology and Evolutionary Biology, University of Arizona, Tucson, AZ 85721, USA. trial organic carbon and nitrogen, information on how urbanization affects soils is important for fully understanding regional to global carbon and nitrogen budgets (Baker et al., 2001; Pouyat et al., 2002). Even though urban soils are estimated to account for only $26.28 \times 10^{14} \mathrm{~g}$ of carbon or roughly $4 \%$ of the carbon in the conterminous United States (Pouyat et al., 2002), cities are among the most dynamic terrestrial ecosystems and this pool of carbon may be changing rapidly. Land-management decisions can play an important role in determining soil characteristics and can have legacy effects on soils lasting for centuries to millennia (Redman, 1999; Compton \& Boone, 2000; Foster et al., 2003). As urbanization is a rapid global transformation occurring primarily in spatially discrete urban areas, local and regional case studies are needed to assess the global impacts of this process (Kaye et al., 2005), with special 
emphasis on multiscale studies linking local and regional patterns (Grimm et al., 2000; Pickett et al., 2001).

Research on urban soils shows that OM and nutrient contents can vary as much within a city as they do across biomes (Pouyat et al., 2002). Decisions that alter urbanized ecosystems occur from scales of individual residences (Martin, 2001) to neighborhoods (Jenerette et al., in review, Massey, 1996) and regions (Oke, 1973; Idso et al., 1998; Luck et al., 2001), with overlaps and nonlinearities between scales. Direct effects of urbanization on soils include physical disturbance, coverage by different materials, management of inputs, and harvest of vegetation. Indirect effects of urbanization on soils include changes in local climate, hydrology, biodiversity and deposition of nutrients, pollutants, and toxins (Pouyat et al., 2002). The consequences of these changes to urban soils can alter vegetation growth (Gregg et al., 2003), soil chemistry (Pouyat et al., 1995, 2002; Zhu \& Carreiro, 2004), nutrient cycling (Carreiro et al., 1999; Groffman et al., 2004; Zhu \& Carreiro, 2004; Pavao-Zuckerman \& Coleman, 2005), trace gas fluxes (Goldman et al., 1995; Kaye et al., 2004, 2005), and belowground communities (Pouyat et al., 1994; Kaye et al., 2005).

Here, we examined the effect of urbanization on multiple-scale spatial variation in soil biogeochemistry for the Phoenix, AZ metropolitan region. Recent nutrient budgets have identified high rates of material fluxes through urban ecosystems (Baker et al., 2001; Groffman et al., 2004). However, the spatial distribution of material storage has not been sufficiently resolved. Our analysis focused on soil OM (SOM), TN and the natural abundance of nitrogen stable isotopes, expressed in 'del' units of parts per thousand ${ }^{15} \mathrm{~N}\left(\delta^{15} \mathrm{~N}\right)$ in comparison with a standard. While components of SOM and TN may cycle rapidly, overall SOM and TN are characterized as slowly changing pools not subject to substantial intraannual variation (Gregorich et al., 1994). In contrast, $\delta^{15} \mathrm{~N}$ may respond more quickly to changing ecological conditions. SOM is a measure of the total mass of living and nonliving organic material within the soil. SOM is often used as a surrogate measure of organic carbon; however, SOM overestimates the soil organic carbon pool. Soil TN is composed of inorganic $\mathrm{NH}_{4}^{+}, \mathrm{NO}_{3}^{-}$, and various organic compounds. Variability in $\delta^{15} \mathrm{~N}$ can provide information on the sources and processing of nitrogen within an ecosystem (Evans \& Ehleringer, 1993; Hoberg et al., 1995; Connin et al., 2001; Amundson et al., 2003).

We present results from a study that uses comparable data sets collected at three nested scales and a comprehensive scaling strategy to evaluate the uncertainty associated with scale translations. Because there are alternative definitions for spatial units, we specifically define these units as used herein. Patch refers to a single land-use and land-cover unit owned by a single agent who manages the unit homogeneously, for example, an agricultural field growing a single crop. Region refers to the entire Phoenix metropolitan area, including both the urbanized core, expanding fringe, and outlying native desert. Landscape refers to any area where spatial heterogeneity is identified, including patches and the region.

We addressed four specific, complementary questions: (1) How much variation in soil $\mathrm{OM}, \mathrm{TN}$, and $\delta^{15} \mathrm{~N}$ exists within individual patches? (2) How does variation in soil OM, TN, and $\delta^{15} \mathrm{~N}$ differ between patch and regional scales? (3) How does the uncertainty of soil $\mathrm{OM}, \mathrm{TN}, \delta^{15} \mathrm{~N}$ mean and variability estimates change with land-use type and scale in the Phoenix metropolitan region? (4) Does urbanization affect soil OM, TN, $\delta^{15} \mathrm{~N}$ within individual patches and for the entire region? Answering these questions for the Phoenix region will provide insights into both the effects of urbanization on soil constituents and strategies for scaling between individual soil samples and broad heterogeneous regions. To address these questions, we developed an empirical spatial-scaling approach that incorporates information from four different scales: points, patches, land-use types, and the region, into a scaling ladder (Wu, 1999). This scaling approach examines the differences in the storage and variability of soil $\mathrm{OM}, \mathrm{TN}$, and $\delta^{15} \mathrm{~N}$ for the entire Phoenix, AZ metropolitan region by comparing the existing desert to the urbanized areas.

\section{Site description}

The Phoenix, AZ metropolitan region lies at the confluence of the Salt and Gila Rivers in central Arizona. The native ecosystem is Sonoran desert scrub and includes primarily the lower Colorado River valley and some of the Arizona upland subbiomes (Turner \& Brown, 1994). The regional climate is hot and dry, with an average (1948-2003) annual daily maximum temperature of $30^{\circ} \mathrm{C}$, average daily minimum of $15^{\circ} \mathrm{C}$, and mean annual rainfall of $193 \mathrm{~mm}$. Precipitation is distributed bimodally with intense summer monsoon storms and longer duration but less intense storms associated with winter frontal systems. The Phoenix metropolitan ecosystem consists of well-delineated patches dominated by agriculture, native desert, and residential land-cover types (Jenerette \& Wu, 2001; Stefanov et al., 2001), with residential patch types mostly falling into two broad landscaping categories: mesic grassy yards and xeric faux-desert (Martin, 2001). Human alterations in the region associated with urbanization have been and continue to be linked with 
changes in agriculture. The landscape impacts of urbanization in this region were detectable up to a distance of at least $75 \mathrm{~km}$ from the urban center in 1995 (Luck \& Wu, 2001).

Urbanized land cover and human population size both increased exponentially over the past 100 years, with the Phoenix metropolitan region reaching 3.3 million human residents by 2004 . If population growth continues on the same trajectory and the relationship between population size and urban area continues, by 2030 the urban area will grow to an extent of $6000 \mathrm{~km}^{-2}$ with a human population of 8 million (Jenerette $\& W u, 2001)$. This rate of urban growth is representative of urbanization within the sun belt of the United States and many arid and semiarid lands globally (Alig \& Healy, 1987; Warren et al., 1996; United Nations Centre for Human Settlements, 2001; Cohen, 2003).

\section{Methods}

\section{Patch sampling}

We intensively sampled two patches each in three landuse types of agricultural, mesic-residential, and native desert ecosystems for a total of six patches. The two patches from each land-use type were not replicate samples, but were meant to bracket the range of heterogeneity within each land-use class. Because many factors in addition to land use influence soil conditions within the ecosystem, our six patches were chosen to represent the most common characteristics of these land-use types within the region (Fig. 1). However, the sampling scheme used may include unaccounted for biases in the representativeness of the sampling grid for the patch, and of each patch for the land-cover classes. The patches sampled in agricultural land use were an alfalfa (Ag1) and a cotton (Ag2) field, the dominant crop types in the region; for the mesic-residential land use an old park, established before 1970 in a lower-income neighborhood (Mes1), and a new park, established after 1995 in an upper-income neighborhood (Mes2) were sampled; and for the native desert patches we sampled a site within the urbanized core surrounded by a mix of land uses (Des1) and one outside the city in an area legally mandated to remain as native desert but actively used for recreation by urban inhabitants (Des2). Like much of the desert beyond urban development, this area has less topographic relief than the remnant desert inside the city.

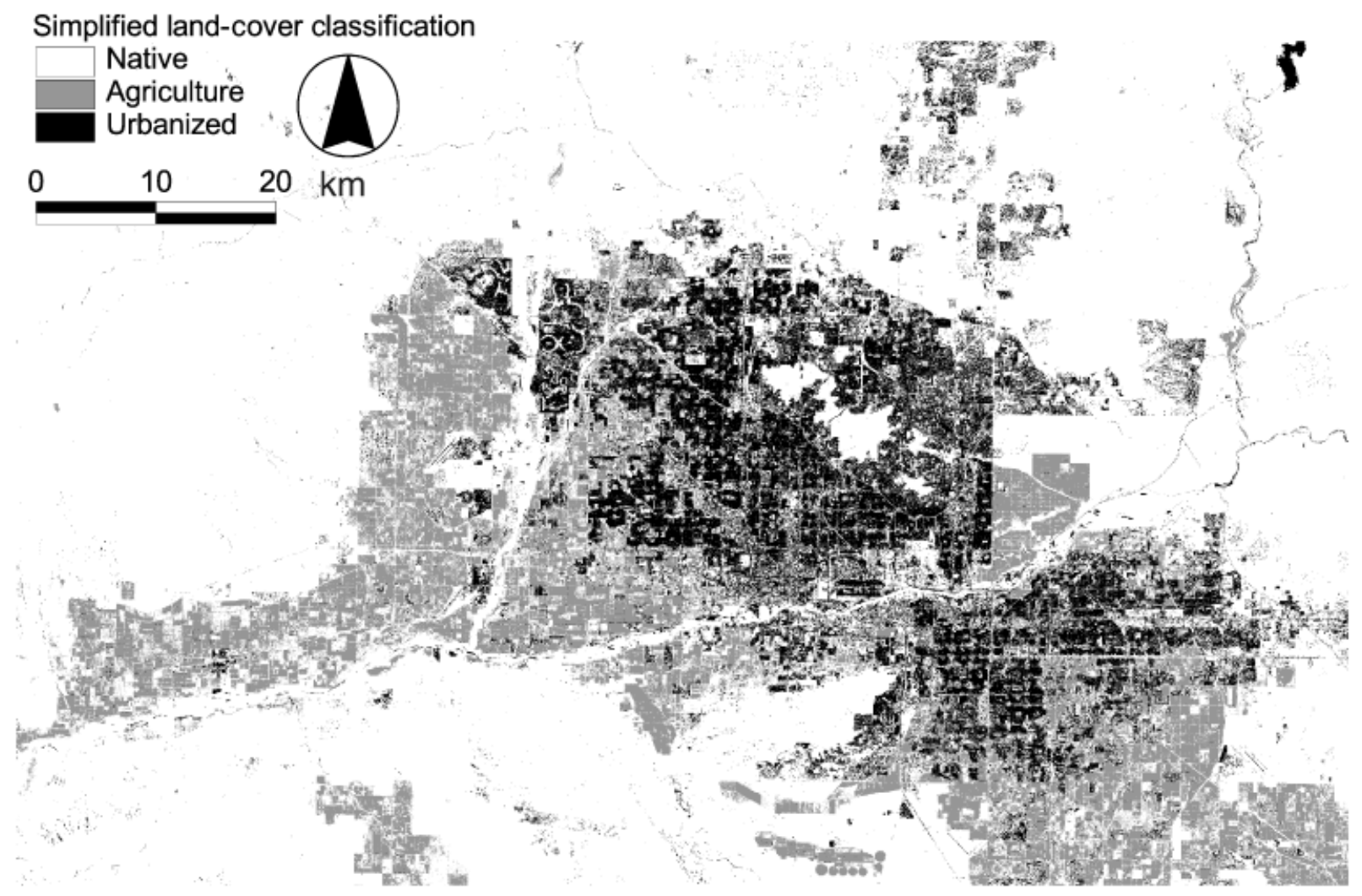

Fig. 1 Landscape pattern in the Phoenix, AZ metropolitan region (modified from Stefanov et al., 2001). This image was generated from an expert classification system that combined satellite and other data to identify patch types. 
Table 1 Mean and coefficient of variation (CV) for OM, TN, and $\delta^{15} \mathrm{~N}$ for each patch, land-use types, and the entire region for the top $10 \mathrm{~cm}$ of soil

\begin{tabular}{|c|c|c|c|c|c|}
\hline & \multirow[b]{2}{*}{ Location } & \multirow[b]{2}{*}{$N$} & \multicolumn{3}{|l|}{ Mean $(\mathrm{CV})$} \\
\hline & & & $\mathrm{OM}\left(\mathrm{kg} \mathrm{m}^{-2}\right)$ & $\mathrm{TN}\left(\mathrm{kg} \mathrm{m}^{-2}\right)$ & $\delta^{15} \mathrm{~N}$ \\
\hline \multirow[t]{6}{*}{ Patches } & Des1 & 94 & $1.69(0.597)$ & $0.050(0.808)$ & $6.492(0.173)$ \\
\hline & Des2 & 94 & $2.25(0.292)$ & $0.053(0.709)$ & $6.115(0.244)$ \\
\hline & Ag1 & 80 & $5.54(0.203)$ & $0.130(0.364)$ & $9.794(0.111)$ \\
\hline & Ag2 & 64 & $6.04(0.152)$ & $0.112(0.271)$ & $8.673(0.142)$ \\
\hline & Mes1 & 96 & $8.24(0.295)$ & $0.271(0.379)$ & $6.539(0.217)$ \\
\hline & Mes2 & 72 & $6.58(0.250)$ & $0.103(0.23)$ & 4.337 (0.177) \\
\hline \multirow[t]{5}{*}{ Land-use types } & Desert & 84 & $2.13(0.387)$ & $0.057(0.671)$ & $6.404(0.265)$ \\
\hline & Agriculture & 29 & $3.37(0.436)$ & $0.083(0.528)$ & $8.347(0.233)$ \\
\hline & Mesic & 62 & $3.48(0.577)$ & $0.099(0.786)$ & $7.342(0.287)$ \\
\hline & Urban & 14 & $3.46(0.714)$ & $0.110(0.965)$ & $7.716(0.220)$ \\
\hline & Other & 15 & $2.36(0.368)$ & $0.067(0.636)$ & $6.745(0.252)$ \\
\hline Regional & & 204 & $0.028(0.567)$ & $0.077(0.812)$ & $7.088(0.279)$ \\
\hline
\end{tabular}

OM, organic matter; TN, total nitrogen.

Intensive sampling of soils was conducted at each site within a 2-week period in April 2002. During this period no rain (or irrigation) was observed, which could have induced transitory changes to many soil biogeochemical variables (Noy-Meir, 1973; Huxman et al., 2004). We used a dual-density, spatially stratified sampling design, establishing a roughly $80 \mathrm{~m} \times 80 \mathrm{~m}$ square grid and locating samples at $10 \mathrm{~m}$ intervals on that grid. Additional sampling points were located randomly within the central $20 \mathrm{~m} \times 20 \mathrm{~m}$ part of the grid for the smallest-scale survey (see Table 1 for final sample sizes from each survey). The size of the actual patch extended between $\sim 1.5$ (Mes2) to more than 100 (Des2) times the sampling grid. The sampling grid was located within each patch such that it fit completely within the patch and was characteristic of the dominant topographic and management patterns of the patch. The grid and all sample locations were mapped using a 'Total Station' laser-based surveying instrument; additional survey points were included to ensure an adequate topographic description of the site. At each sampling location we measured elevation and slope and collected a $5.08 \mathrm{~cm}$ diameter $\times 10 \mathrm{~cm}$ deep soil core. A $10 \mathrm{~cm}$ core was chosen as a standard for comparison between patches and additional regional monitoring. Cores were transported to the laboratory in coolers and refrigerated $\left(5{ }^{\circ} \mathrm{C}\right)$ before determination of water content, stone content, bulk density, TN, $\delta^{15} \mathrm{~N}$, and SOM.

\section{Regional sampling}

Soil samples at the regional scale were collected during the spring of 2001 as a primary long-term monitoring component of the Central Arizona-Phoenix Long Term
Ecological Research (CAP-LTER) project. The sampling region was centered on the Phoenix urban core and extended into the outlying native desert encompassing a total extent of $6400 \mathrm{~km}^{2}$. The sampling scheme for the regional study consisted of a dual-density, tessellationstratified randomized design with 204 survey sites (Hope et al., 2003). Soil cores were collected from four locations within each $30 \mathrm{~m} \times 30 \mathrm{~m}$ survey site. The top $10 \mathrm{~cm}$ sections of the four replicate soil cores from each survey site were mixed to give a single sample per site and processed as described below. Data on soil inorganic $\mathrm{N}$ concentrations, net $\mathrm{N}$ mineralization and nitrification, SOM, bulk density, and water content from this large survey have been presented elsewhere (Zhu et al., in press, Hope et al., in press). The SOM and bulk density data are again presented but here subjected to scaling analyses, whereas for $\mathrm{TN}$ and $\delta^{15} \mathrm{~N}$ new chemical analyses were conducted using archived soil samples.

\section{Laboratory analyses}

Water content was determined as mass loss between fresh and oven-dried $\left(60^{\circ} \mathrm{C}\right.$, until mass stabilized) samples. Gravel-free bulk density was determined from dry mass of soil divided by the volume of the soil core. The high clay content of many samples caused clumping during drying; clumps were manually ground until they passed through a $2 \mathrm{~mm}$ sieve. Soil samples thus processed were then subsampled for subsequent analyses of SOM and TN, as well as $\delta^{15} \mathrm{~N}$. SOM concentration was estimated using mass loss-on-ignition $\left(550{ }^{\circ} \mathrm{C}\right.$, $6 \mathrm{~h})$. Soil TN concentration and $\delta^{15} \mathrm{~N}$ were determined using a PDZ-Europa Hydra GSL 20/20 Isotope Ratio 
Mass Spectrometer, which gave both \% total $\mathrm{N}$ and isotopic ratios for each sample. Pool sizes were estimated by multiplying concentration by bulk density. The $\delta^{15} \mathrm{~N}$ values are a standardized measure of the ratio of $\mathrm{N}$ isotopes in the sample:

$$
\delta^{15} \mathrm{~N}=\left[\left(R_{\text {sample }} / R_{\text {standard }}\right)-1\right] \times 1000,
$$

where $R$ is the ${ }^{15} \mathrm{~N}:{ }^{14} \mathrm{~N}$ ratio in sample or standard, which for $\mathrm{N}$ is the atmosphere (Peterson \& Fry, 1987).

\section{Statistical analyses}

Statistical analyses were conducted to address questions posed earlier relating to variation in soil properties within and across scales and land-use types. As a brief overview, our analysis characterized the mean and variability observed within each patch (Question 1) and compared the patterns observed in each data set (Question 2). Estimates of means and uncertainties for each land-use type were generated through a linkage of the patch and regional data (Question 3). We then upscaled estimates of $\mathrm{OM}$ and TN storage and values of $\delta^{15} \mathrm{~N}$ by combining the land-use type estimates with a classified satellite map of land-use distributions allowing for an assessment of the urbanization effect (Question 4). These analyses were addressed using Monte Carlo and bootstrapping techniques, which are especially useful for estimating statistical properties of nonparametric distributions (Potvin \& Roff, 1993).

To describe the variation within each data set we calculated means and standard deviations for each patch, land-use type, and for the entire region. To compare variation between the different scales, we computed a ratio of the $\mathrm{CV}$ between the regional data and each other data set:

$$
\mathrm{CV} \text { ratio }=\left(\frac{\left(\mathrm{CV}_{1}-\mathrm{CV}_{2}\right)}{\left(\mathrm{CV}_{1}+\mathrm{CV}_{2}\right)}\right)^{2} \text {, }
$$

where $C_{1}$ is the $C V$ in any data set except the regional survey and $\mathrm{CV}_{2}$ was the $\mathrm{CV}$ observed in the regional survey. Similar to other uses of CV ratios (Tilman et al., 1998), Eqn (2) normalizes the CV ratio to a value between 0 and 1 . As the $\mathrm{CV}$ ratio increases, the difference in variation between each data set increases.

To describe the spatial-scaling characteristics of soil properties and their variation between patch and regional scales, we computed empirical scaling relationships. Spatial scaling patterns within each patch and the entire region were examined using a Monte-Carlo scalevariance estimator, which computed the relationship between area and variance within the landscape. Each landscape was resampled at 100 equal interval scales between two times the minimum interspace distance between sampled points and 50\% the extent of the original field survey. For each of these resampling iterations 10000 circular quadrats were randomly located and if a circle included more than three sample points the standard deviation of each variable was computed for each circle. From the resulting scalevariance patterns, scaling equations (Eqn (3)) were estimated from the relationship between quadrat area and variability, as described by the standard deviation.

$$
V=c A^{z}
$$

Equation (3) describes the variability $(V)$ as a function of a constant $(c)$, sampling area $(A)$, and a scaling exponent $(z)$. Scaling exponents $(z)$ for each data set were computed using regression analysis.

Upscaling from individual sampling points to estimates of land-use type estimates was conducted using two scaling ladders, a point-to-patch rescaling and a patch to land-use type rescaling. The uncertainty associated with each scale translation was empirically estimated. Point-to-patch scaling uncertainty was the uncertainty associated with estimating the patch average from a spatially limited homogenized sample. Similar to the scale-variance estimator, we used a spatially explicit Monte-Carlo subsampling of the fieldcollected data. The algorithm randomly placed 10000 circular quadrats of constant size on the landscape and computed the deviation between the observed patch mean and the mean within a single quadrat. The MonteCarlo uncertainty estimate for scaling between the point and patch scale was generated using the following equation:

$$
U_{\text {Monte Carlo }}=\frac{\sum_{i=1}^{j} x_{i} / j-X}{\sum_{i=1}^{j} x_{i} / j}
$$

Equation (4) describes the uncertainty associated with each Monte-Carlo subsample $\left(U_{\text {Monte Carlo }}\right)$ as a function of the entire sample mean $(X)$ and each data point within the Monte-Carlo subsample $\left(x_{i}\right)$. This value is then normalized by the subsample mean. The width of the $95 \%$ uncertainty patch estimate for a given subsample size was computed as the difference between the 97.5 and 2.5 percentiles of the Monte-Carlo uncertainty estimators. We computed the uncertainty estimates for a $15 \mathrm{~m}$ radius circle that coincides with the field sampling protocol for the regional data. Furthermore, we identified the radius required to reduce the point-to-patch scaling uncertainty to $10 \%$ of the patch mean.

In scaling to land-use class estimates, we linked the point-to-patch uncertainty with the regional data using a combined bootstrapping and Monte-Carlo analysis. All of the samples from the regional survey were assigned to a land-use type based on a field determina- 
tion. Land-use classes included the mesic grass, agricultural, and native desert land-use types sampled at the patch scale. Additional land-use classes observed in the field were aggregated into an urban class, which included industrial, commercial, and transportation corridors, and an 'other' class, which included all other land uses that did not fit into the previous classes. Each of the field samples was considered representative of a patch whose uncertainty could be modeled from the empirically derived point-to-patch scaling analysis. To generate means and uncertainties or soil properties associated with each land-use type 10000 bootstrapped samples were obtained from the appropriate land-use subset of the regional data. When a data point was selected for inclusion in a bootstrapped sample, the value was modified by a Monte-Carlo draw from the point-to-patch uncertainty distribution. Point-to-patch uncertainty distributions for each land-use type were obtained from the corresponding uncertainty observed in the two patches of the same land-use type (i.e. desert, agriculture, and mesic). For the land-use types we did not sample at the patch level, uncertainty was approximated as the combined point-to-patch uncertainty. Using the analysis generated from Eqn (4) we computed the land-use type and variable-specific uncertainty associated with scaling from individual points to landuse types.

Combining the land-use type estimate with classified satellite land-cover map (Stefanov et al., 2001) (Fig. 1), we estimated the total $\mathrm{OM}$ and TN stored within the different land-use types of the Phoenix, AZ metropoli$\tan$ region. A conservative effect of urbanization on regional soil $\mathrm{OM}, \mathrm{TN}$, and $\delta^{15} \mathrm{~N}$ was estimated as percent change, using the assumption that the native desert before urbanization could be approximated by the pattern in the extant desert.

\section{Results}

\section{Patch and land-use analyses}

Large variation was observed within each patch, within each land-use type, and throughout the entire Phoenix metropolitan region for $\mathrm{OM}, \mathrm{TN}$, and $\delta^{15} \mathrm{~N}$ (Table 1). Mes1 had the highest SOM content and the two desert sites the lowest. Results for TN showed a similar pattern. The $\delta^{15} \mathrm{~N}$ values were highest in the agricultural fields, intermediate in the desert, and lowest in the mesic yards. Differences in patch means varied by factors of 4.9, 5.5, and 2.3 for $\mathrm{OM}, \mathrm{TN}$, and $\delta^{15} \mathrm{~N}$, respectively. Differences among land-use types means at the regional scale were in the lower range of the variation exhibited at the patch scale for $\mathrm{SOM}$ and $\mathrm{TN}$, but were nearer to the median values for $\delta^{15} \mathrm{~N}$. In

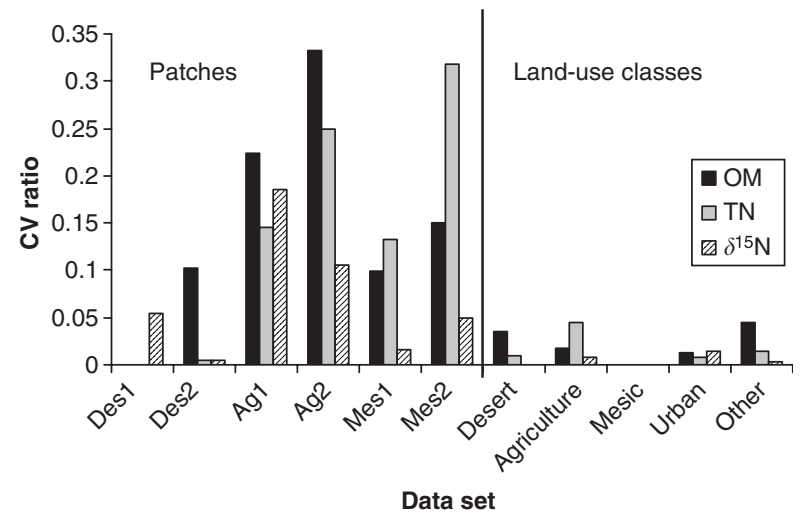

Fig. 2 The ratio between the regional coefficient of variation (CV) and the CV within individual patches and land-use classes. The ratio rescales the variation at finer scales to the variation observed from the entire region allowing comparisons between the variation observed in individual patches and land-use classes.

general, the variation at the regional scale was more similar to the land-use type than the patch scale, as determined by the $\mathrm{CV}$ ratio between each sampling group and the regional pattern with Eqn (2) (Fig. 2). Variability in the mesic land-use class was nearly indistinguishable from regional-scale variability. Variation at the regional scale was larger than observed in the other patches or individual land-use types except for Des1, Mesic and Urban for OM, Urban for TN, and Mesic for $\delta^{15} \mathrm{~N}$ (Table 1).

The amount of variation observed within patches and land-use types differed. Within-patch variability in OM was highest at Des1; TN variability was highest in both desert patches; $\delta^{15} \mathrm{~N}$ variability was highest in Des1, while other patches showed similar amounts of variation (Fig. 2). Differences in patch CV varied by factors of $3.9,3.6$, and 2.2 for $\mathrm{OM}, \mathrm{TN}$, and $\delta^{15} \mathrm{~N}$, respectively (Table 1). Within-land-use variability in $\mathrm{OM}$ was highest in urban and mesic land uses; TN variability was also highest in urban and mesic land uses; and $\delta^{15} \mathrm{~N}$ variability was highest in desert and mesic land uses (Table 1). Differences in land-use CV varied by factors of $1.9,1.8$, and 1.3 for $\mathrm{OM}, \mathrm{TN}$, and $\delta^{15} \mathrm{~N}$, respectively.

\section{Scaling analyses}

Generating scalograms for spatial scaling of variability allowed us to compute scaling exponents, $z$ (Fig. 3a). For all scalograms the power-law scaling equation fit with $R^{2}>0.80$, suggesting that the resulting exponents were appropriate descriptors of the scaling relations. The scaling exponents showed a large range of variability that was idiosyncratic for individual patches. 

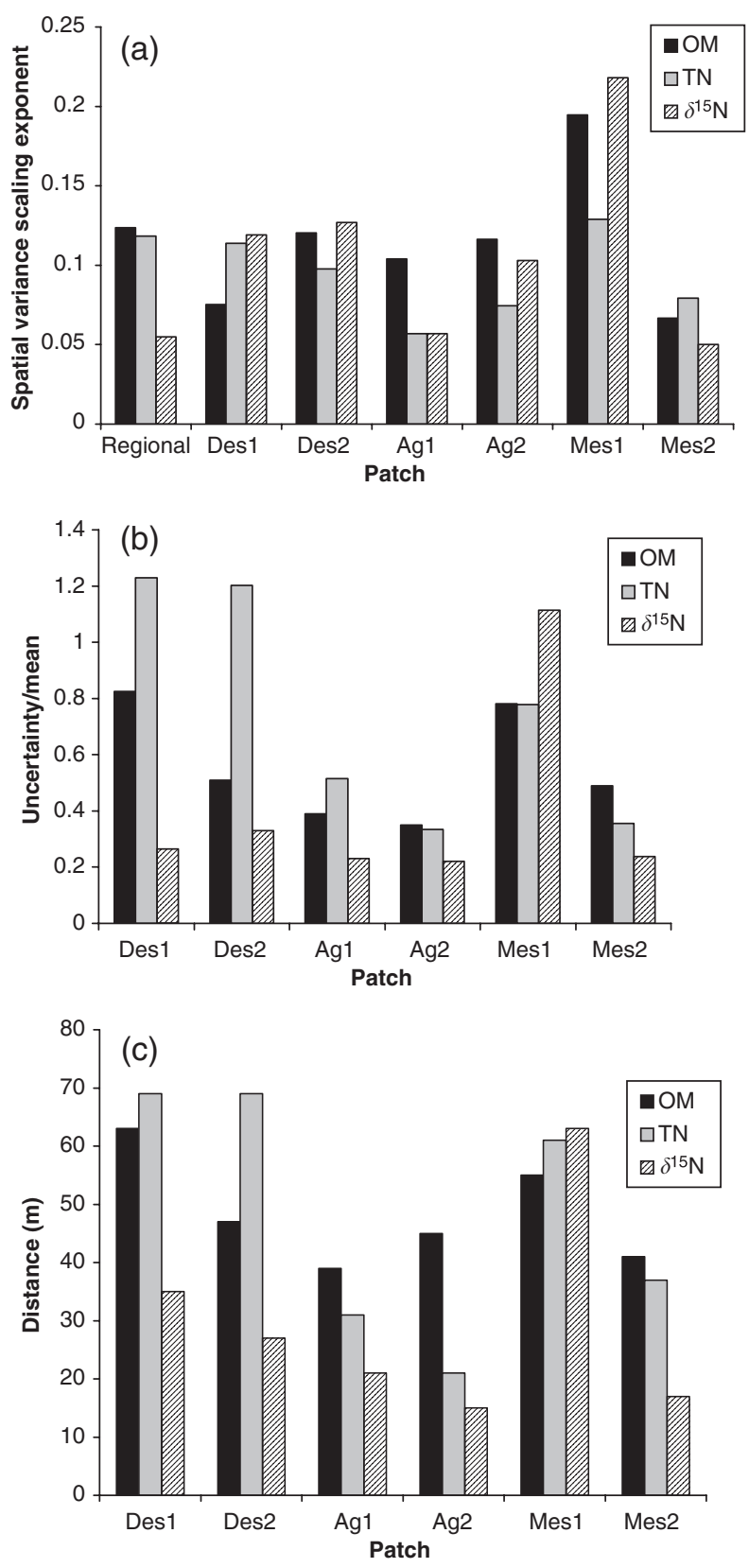

Fig. 3 Scaling properties. (a) Variance spatial scaling exponents between patches and the entire region. (b) Estimated uncertainty associated with scaling from a $15 \mathrm{~m}$ radius circle to the patch. Uncertainty has been scaled to the patch mean to show relative differences between sites and between variables. (c) Sampling distance (radius of circle) required to reduce scaling estimate to $10 \%$ of observed mean patch value.

Our estimate of point-to-patch uncertainty allowed us to quantify the potential error in upscaling to patch estimates. At the $15 \mathrm{~m}$ sampling radius we observed uncertainties ranging between $22 \%$ and $123 \%$ of the patch mean (Fig. 3b). The two desert and agricultural

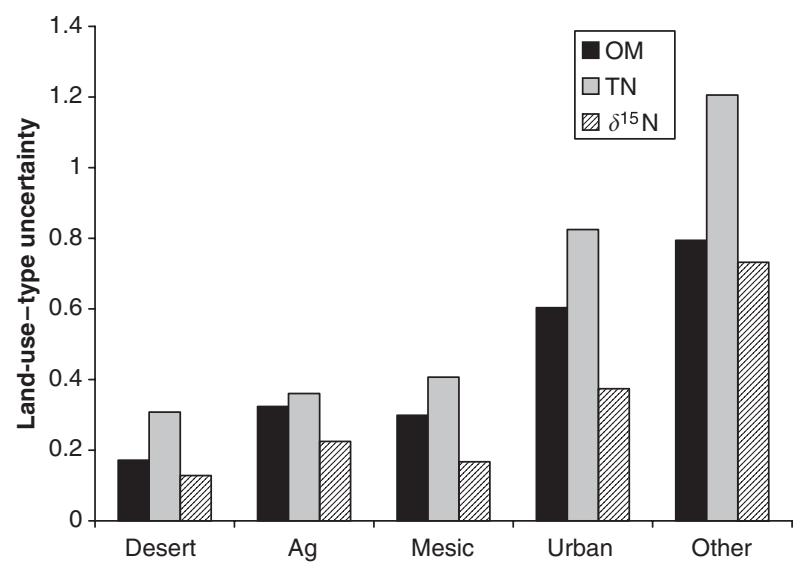

Fig. 4 Uncertainty associated with scaling to patch type estimates of mean organic matter, soil total nitrogen, and $\delta^{15} \mathrm{~N}$ for the Phoenix, AZ metropolitan region. Uncertainty was assessed using combined Monte-Carlo and bootstrapping approaches.

patches had similar patterns of uncertainty for SOM, TN, and $\delta^{15} \mathrm{~N}$. The mesic sites did not show as consistent a pattern. To compare with the uncertainty at a $15 \mathrm{~m}$ radius, we also computed the radius of sample required to reduce uncertainty to $10 \%$ of the observed mean patch value (Fig. 3c).

Again, the sampling area that was required to reduce the uncertainty of both the two desert and agricultural patches were consistent within their land-use type. The desert patches required a larger area in both cases for reducing uncertainty than agricultural patches. The two mesic patches varied in the sampling area required for resampling. Incorporating the point-to-patch scaling uncertainty with the patch-to-land-use-type scaling uncertainty allowed for a comprehensive estimate of uncertainty inherent in scaling to each land-use type (Fig. 4). The desert sites had the highest uncertainty when scaling from points to patches (Fig. 3b,c); however, when scaling to land-use type, uncertainties in the desert were generally lowest. Scaling uncertainties in agricultural and mesic patch types were similar to each other. In contrast, uncertainty was high for estimates of the nonmesic urban patches. From the bootstrapping uncertainty analysis (Eqn (4)) we derived estimates of means for each land-use type and with associated 95\% confidence intervals (Fig. 5).

\section{Estimation of regional soil pools}

By combining estimates of mean soil OM, TN, and $\delta^{15} \mathrm{~N}$ for each land-use type and uncertainties for each soil variable with the area of each land-use type, we computed total SOM and TN stored within urbanized patches of the Phoenix, AZ metropolitan region (Table 2). 

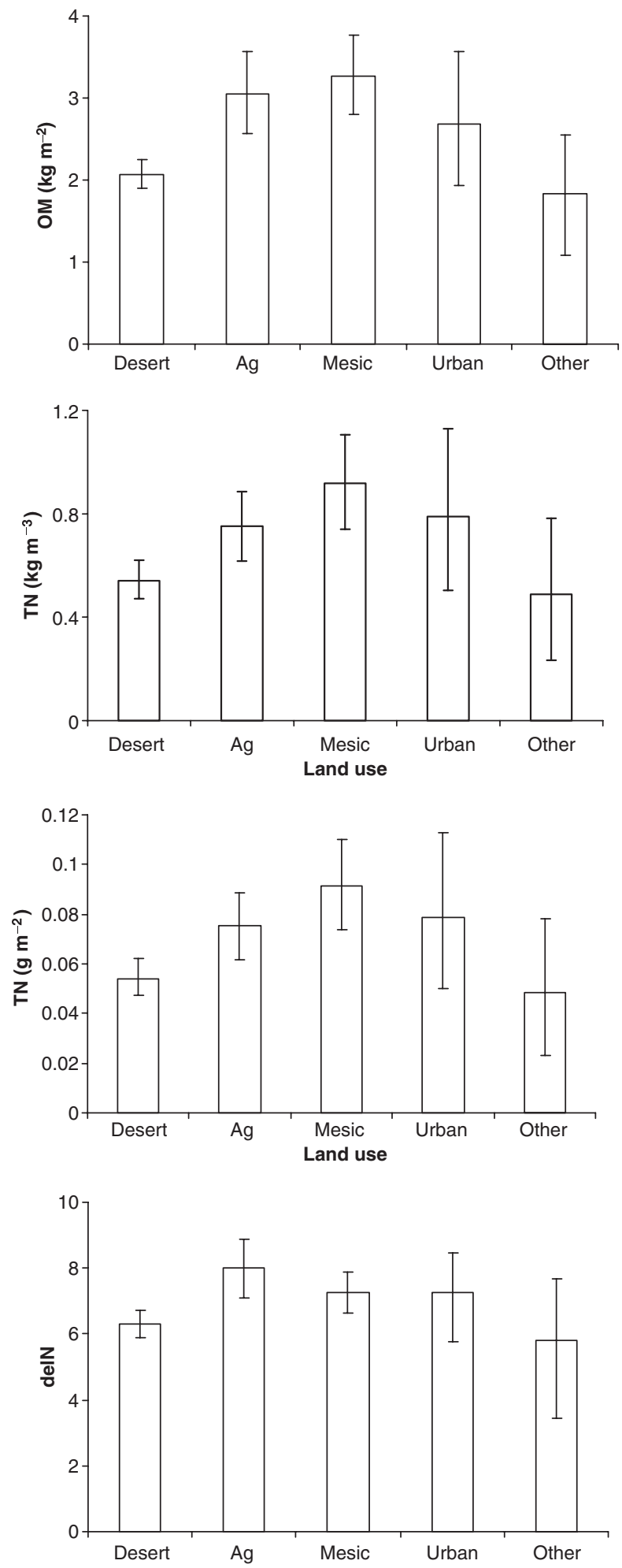

Fig. 5 Regional land-use type estimates of soil organic matter, soil total nitrogen, and $\delta^{15} \mathrm{~N}$ with $95 \%$ confidence intervals assessed through a combined Monte-Carlo and bootstrapping uncertainty analysis.
Table 2 Estimated change in soil OM and TN storage due to urbanization in the Phoenix, AZ metropolitan region compared with native desert

\begin{tabular}{llllll}
\hline & Agriculture & $\begin{array}{l}\text { Mesic } \\
\text { yard }\end{array}$ & Urban & Total & $\begin{array}{l}\% \\
\text { increase }\end{array}$ \\
\hline $\begin{array}{l}\text { Area } \\
\left(\mathrm{km}^{2}\right)\end{array}$ & 735.9 & 208.6 & 532.0 & 1476.5 & na \\
$\mathrm{OM}(\mathrm{kg})$ & $6.75 \times 10^{9}$ & $2.18 \times 10^{9}$ & $4.29 \times 10^{9}$ & $1.32 \times 10^{10}$ & 44 \\
$\mathrm{TN}(\mathrm{kg})$ & $1.66 \times 10^{9}$ & $6.18 \times 10^{8}$ & $1.26 \times 10^{9}$ & $3.48 \times 10^{9}$ & 48 \\
\hline
\end{tabular}

These values are estimated to a $10 \mathrm{~cm}$ depth. $\mathrm{OM}$, organic matter; $\mathrm{TN}$, total nitrogen.

Amounts of SOM and TN stored in urbanized land-use types were $44 \%$ and $48 \%$ higher, respectively, than in the desert land-use type. Using an area-weighted average $\delta^{15} \mathrm{~N}$, we can similarly estimate its modification by urbanization compared with native desert: an enrichment of $\delta^{15} \mathrm{~N}$ values by $21 \%$ compared with native desert $\delta^{15} \mathrm{~N}$ values.

\section{Discussion}

\section{Variation within and between patches and scales}

The amount of variation in soil $\mathrm{OM}, \mathrm{TN}$, and $\delta^{15} \mathrm{~N}$ occurring within (Question 1) and between (Question 2) individual patches, land-use types and the entire metropolitan region was addressed by computing the mean and $\mathrm{CV}$ for each variable for each patch, for each land-use type, and for the entire region (Table 1). As found in previous research showing substantial differences in spatial heterogeneity between apparently similar sites (Robertson et al., 1993, 1997), we also observed distinct spatial patterns within each landscape that were independent of land use. Proceeding from patches to land-use types and the region, more variation was generally observed at coarser scales. All land-use types, human-constructed and native, exhibited similar amounts of variation between patches and between land-use types. However, the desert and human-constructed land-use types differed in how their variation was distributed across scales. The majority of variation in the desert land-use type was observed within a single patch, whereas for mesic and agricultural land-uses, most variation was observed between distinct patches. Increased homogeneity within individual patches likely results from consistent management by individual owners. Increased heterogeneity between patches likely results from alternate strategies used by diverse owners with contrasting objectives.

For a complementary approach to understanding the variation between scales, we derived scalograms from 
the relationship between area and variability. While patterns within a landscape were accurately described by power-law scaling relationships, the scaling exponents varied considerably between patches, land-use types, and the region. These results suggest that the spatial patterns of soil $\mathrm{OM}, \mathrm{TN}$, and $\delta^{15} \mathrm{~N}$ are responding to distinct drivers operating at distinct scales; thus, a scaling approach that separates heterogeneity into bounded scale domains is appropriate.

The uncertainty of soil SOM, TN, and $\delta^{15} \mathrm{~N}$ storage and variability differs throughout the Phoenix metropolitan region (Question 3). We specifically examined uncertainty at two different scales: (1) point-to-patch scaling within six different patches and (2) patchto-land-use-type scaling. Whereas the uncertainty associated with scaling from point to patch varied considerably by variable and patch of interest, patchto-land-use-type scaling, which included estimated point-to-patch uncertainty, showed consistent trends across variables. Land-use-type uncertainty increased from $\delta^{15} \mathrm{~N}$ to SOM to TN; scaling errors varied systematically by variable of interest and not by land-use type (Fig. 4). Patch-to-land-use-type scaling had the lowest uncertainty in the desert patch type and highest in the human-constructed land-use types.

The majority of variation in the desert patches was observable within an individual patch. In contrast, the majority of variation in agricultural and mesic patch types was observed between distinct patches. Previous analyses of soil inorganic $\mathrm{N}$ from a geostatistical perspective and of the patterns in inorganic soil $\mathrm{N}$ across the CAP-LTER site (Hope et al., in press) showed that at the regional scale, shallow (top $10 \mathrm{~cm}$ ) soil $\mathrm{NO}_{3}-\mathrm{N}$ concentrations were spatially autocorrelated between sites in undeveloped desert but not between points within the developed urban area.

These findings suggest that intensive human management decreases heterogeneity of soil properties within individual patches but increases heterogeneity between patches, compared with the native desert (Figs $3 b$ and 4). Urbanization appears to have reduced the variability of both physical and biological properties of soils within individual patches, up to the $100 \mathrm{~m}$ scale window examined, within the Phoenix metropolitan region. Since patch size varies as a function of distance from urban core (Luck et al., 2001b), we hypothesize that the spatial scale of variability - and therefore the spatial scale of dominant processes - may also vary along an urban-rural gradient.

\section{Human modification of regional soils}

Urbanization and agriculture has enhanced the abundance of SOM, TN, and $\delta^{15} \mathrm{~N}$ in surface soils (top $10 \mathrm{~cm}$ ) of the Phoenix, AZ metropolitan region (Question 4). The magnitude of these changes is proportional to area occupied by each land-use type in the region; misclassification of land use may and ongoing urban expansion will alter the area of each land-use type and therefore estimates of the urbanization effect. Mesic landscaping in Phoenix (i.e., the installation of watered lawns, leafy shrubs, and shade trees) increases soil carbon, nitrogen and organic matter compared with native desert patches (Green \& Oleksyszyn, 2002). Moreover, both agricultural and urban residential soils exhibit a legacy of past land use that persists for decades as elevated SOM and N (Lewis et al., 2006). Our findings support these previous results in terms of direction and general magnitude of pool-size changes. The higher SOM in agricultural compared with native desert soils seen in this study is contrary to the more typical result (at least in mesic systems) that agricultural soils are associated with a decreased SOM (Lal, 1998). Our results suggest a larger increase in nitrogen associated with urbanization than do Zhu et al. (in press); however, this discrepancy may be explained by differences in approach. They calculated increases only for inorganic pools, which are much smaller than total pools, selected a lower baseline soil $\mathrm{N}$ content to highlight the effects of unknown aspects of urbanization that were not specific to land-use types, and they extrapolated to the urban and nonurban components of the region. Changes in the $\delta^{15} \mathrm{~N}$ ratio suggests that human activities are not just altering the material storage of $\mathrm{TN}$ but are systematically modifying processes within the nitrogen cycle, as changes in $\delta^{15} \mathrm{~N}$ result from a variety of mechanisms reflecting both inputs and internal processes.

Our results are comparable with previous findings in arid regions. Arid and semiarid soils typically consist of between $0.5 \%$ and 1.5\% SOM (Titus et al., 2002), with concentrations highest in the top soil layers (Peterjohn \& Schlesinger, 1990). The mean stored nitrogen estimated in a budget of southwestern US aridlands is higher than we report from the desert patches in this study by $0.45 \mathrm{~kg} \mathrm{~N} \mathrm{~m}^{-3}$; however, our observations are well within the variation described in this budget and other studies, which ranged from 0.105 to $0.831 \mathrm{~kg} \mathrm{~N} \mathrm{~m}^{-3}$ (West \& Klemmedson, 1978; Post et al., 1985; Peterjohn \& Schlesinger, 1990). In a study of the arid intermountain western United States, $\delta^{15} \mathrm{~N}$ values varied between 4.0 and 9.0 and were negatively related to soil total N (Evans et al., 1993), while globally, arid soils have a $\delta^{15} \mathrm{~N}$ varying between 1.5 and 5.9 (Amundson et al., 2003). To our knowledge, this study is the first to describe the variation in soil $\delta^{15} \mathrm{~N}$ within a city. Uncovering the mechanisms producing $\delta^{15} \mathrm{~N}$ variation in the Phoenix, AZ metropolitan region should help identify the missing sink observed in the regional 
nitrogen budget (Baker et al., 2001). Urbanization in the Phoenix, AZ metropolitan region has altered key biogeochemical patterns that generally respond slowly to environmental drivers and likely will leave an extensive legacy affecting future biogeochemical patterns within this region.

The Phoenix, AZ metropolitan region, unlike more mesic urbanized regions (Pouyat et al., 1995; McDonnell et al., 1997; Pouyat \& Carreiro, 2003; Zhu \& Carreiro, 2004; but see Bennett, 2003), does not exhibit a readily apparent urban-to-rural gradient in the mean value of soil, vegetation, or climate patterns (Hope et al., 2003, in press; Jenerette et al., in review). This difference may be attributable to differences in the structure of Phoenix, AZ and more mesic cities; Phoenix has a generally uniform population density within the urbanized components and an abrupt edge between adjacent urban and native land-use types.

How applicable are these findings to other cities? In other arid regions we expect the construction of agricultural fields and mesic yards will have similar withinpatch effects to those we observed, although the effects on regional soil pools are likely to differ due to the proportions of each land-use type. For cities in more mesic biomes, we might expect an opposite trend - with conversions to agriculture and lawns resulting in lower quantities of organic matter and total nitrogen in the soil than in the native soils. In support of this contention, the Lower Fraser Basin, a temperate rain forest region in southwestern British Columbia, Canada, has exhibited a substantial decrease in carbon storage associated with land-use change (Boyle \& Lavkulich, 1997). Pouyat et al. (2002) hypothesized that urban soils in the arid Southwest would have elevated carbon pools relative to native soils compared with cities in temperate climates, a hypothesis our results support when compared with the results of Boyle \& Lavkulich (1997). Uncovering the mechanisms behind such differences among biomes is an important research challenge for understanding continental and global variation in the effects of urbanization.

\section{Scaling}

An explicit examination of scaling approaches is needed to address many questions in ecology (King, 1991; Rastetter et al., 1992) and assessing rates of global change (Wessman, 1992; Osmond et al., 2004). Linked top-down and bottom-up scaling approaches are especially needed to identify the combined consequences of diverse human activities on terrestrial ecosystems (Canadell et al., 2000). Scaling analyses are useful for revealing insights into the consequences of multiple drivers affecting ecosystem patterns (Wu et al., 2005).
Perhaps most pressing is the need for strategies to upscale ground measurements to provide verification for coarse-resolution remotely sensed products such as MODIS (Turner et al., 2004). As used in our study, combining observations from multiple scales with Monte-Carlo-derived estimates of uncertainty at different hierarchical levels is one approach for addressing these issues (Katz, 2002). A diverse suite of scaling theories has developed (O'Neill, 1989; King, 1991; Milne, 1998; Wu et al., 2005) that emphasizes both the similarity in patterns within domains of scale (Barenblatt, 1996; Schneider, 2001) and discontinuities in patterns between domains of scale (O'Neill et al., 1986; Holling \& Gunderson, 2002). Many ecosystem patterns and processes exhibit consistency in scaling over limited domains of scale (Milne et al., 2002; Wu, 2004). Within individual scaling domains, captured by our regional and patch surveys, power-law scaling based on similarity theory was effective as shown by the high $r^{2}$ values $(>0.8)$ for relationships between sample area and sample variation. Important scale breaks were observed at the within-patch and between-patch boundary in the Phoenix metropolitan region, when comparing six distinct patches and the entire region. As suggested by these scale differences, a hierarchical scaling ladder approach (Wu, 1999) incorporating domains of similarity and discontinuities between scaling domains, provides a conceptual approach for recognizing the importance of both scale similarity and scale discontinuities.

A central component of spatial scaling is the determination of uncertainty (Williams et al., 2001; Katz, 2002). Through this study we developed a comprehensive approach to scaling and uncertainty assessment between points, patches, land-use types and the region. In our approach, five sources of uncertainty potentially exist: measurement uncertainty, patch uncertainty, land-use type uncertainty, mapped uncertainty, and finally, regional uncertainty. Simply adding uncertainty from each stage is inappropriate, as uncertainty often propagates between scales in a nonlinear fashion $(\mathrm{Wu}$ et al., 2005). Indeed, we observed declining uncertainty when moving from an individual patch to estimates of the land-use types. By identifying a scaling ladder and computing associated uncertainty in a series of discrete steps, our results support the usefulness of a compromise between self-similarity and hierarchically based spatial scaling. Such an approach will be useful for linking landscape structure analyses to ecological patterns and processes in a variety of ecosystems - wild, rural, and urban. The scaling approach outlined here can be more generally applied for linking local and regional observations to quantify the uncertainty associated with estimates of global change. 


\section{Conclusions}

Cities, by virtue of highly concentrated human activities, are important locations for the interactions between ecological and social systems. While often excluded or assumed to be similar to native ecosystems, urbanization substantially alters soil organic matter and nitrogen patterns. Assessing ecosystem response to the multiple-scale sources of variation within a city provides insight into the linkages between social and ecological components. Within a city these linkages between society and ecosystems occur at multiple scales ranging from individual patches to the urbanized region as a whole. Characterizing the scaling relationships helps in understanding the determinants of ecosystem patterns. While the uncertainty associated with scaling from point to patch varied considerably by variable and patch of interest, patch to land-use type scaling showed consistent trends across variables. Compared with the remaining undeveloped desert, urban soils have larger pools of organic matter and total nitrogen and less variability at scales below $100 \mathrm{~m}$. However, because the number of surveys conducted within individual patches were limited, further research within individual patches and at the interfaces between patches is still needed. Land use is a strong predictor of local pool sizes and variability within a patch, but we have shown that the spatial distribution of this variation may itself vary substantially throughout a city. As direct human-ecological interactions are increasingly occurring within urbanized landscapes, understanding the connections between humans and urbanized ecosystems will increase in importance both for basic understanding and ensuring the sustainability of these high-density human habitats.

\section{Acknowledgements}

We thank John Briggs, Doug Green, Corrina Gries, Jason Kaye, Jake Oleson, and Weixing Zhu for constructive discussions regarding this research. Leon DeOliver, Jennifer Edmonds, Jim Heffernan, Wendy Marussich, John Roach, John Schade, and Jill Welter provided invaluable field assistance. We thank the 2000 Survey 200 crew for their hard work in the field and laboratory generating the regional dataset. This research was supported by the National Science Foundation via the CAP-LTER (DEB 9714833 and DEB 04-23704), and Urban Ecology IGERT (DGE9987612), and the US Environmental Protection Agency's Science to Achieve Results program (R827676-01-0).

\section{References}

Alig RJ, Healy RG (1987) Urban and built-up land area changes in the United States - an empirical-investigation of determinants. Land Economics, 63, 215-226.
Amundson R, Austin AT, Schuur EAG et al. (2003) Global patterns of the isotopic composition of soil and plant nitrogen. Global Biogeochemical Cycles, 17, art. no. 1031. doi: 10.1029/ 2002 GB001903.

Baker LA, Hope D, Xu Y et al. (2001) Nitrogen balance for the central Arizona-Phoenix (CAP) ecosystem. Ecosystems, 4, 582-602.

Barenblatt G (1996) Scaling, Self-Similarity, and Intermediate Asymptotics. Cambridge University Press, Cambridge.

Bennett EM (2003) Soil phosphorus concentrations in Dane County, Wisconsin, USA: an evaluation of the urban-rural gradient paradigm. Environmental Management, 32, 476-487.

Beyer L, Blume HP, Elsner DC et al. (1995) Soil organic-matter composition and microbial activity in urban soils. Science of the Total Environment, 168, 267-278.

Boyle CA, Lavkulich L (1997) Carbon pool dynamics in the lower fraser basin from 1827 to 1990. Environmental Management, 21, 443-455.

Canadell JG, Mooney HA, Baldocchi DD et al. (2000) Carbon metabolism of the terrestrial biosphere: a multitechnique approach for improved understanding. Ecosystems, 3, 115-130.

Carreiro MM, Howe K, Parkhurst DF et al. (1999) Variation in quality and decomposability of red oak leaf litter along an urban-rural gradient. Biology and Fertility of Soils, 30, 258-268.

Cohen JE (2003) Human population: the next half century. Science, 302, 1172-1175.

Compton JE, Boone RD (2000) Long-term impacts of agriculture on soil carbon and nitrogen in New England forests. Ecology, 81, 2314-2330.

Connin SL, Feng X, Virginia RA (2001) Isotopic discrimination during long-term decomposition in an arid land ecosystem. Soil Biology and Biochemistry, 33, 41-51.

Craul PJ (1985) A description of urban soils. Journal of Arboriculture, 11, 330-339.

Evans RD, Ehleringer JR (1993) A break in the nitrogen-cycle in aridlands: evidence from delta-N-15 of soils. Oecologia, 94, 314-317.

Foster D, Swanson F, Aber J et al. (2003) The importance of landuse legacies to ecology and conservation. Bioscience, 53, 77-88.

Goldman MB, Groffman PM, Pouyat RV et al. (1995) Ch4 uptake and $\mathrm{N}$ availability in forest soils along an urban to rural gradient. Soil Biology and Biochemistry, 27, 281-286.

Green DM, Oleksyszyn M (2002) Enzyme activities and carbon dioxide flux in a Sonoran desert urban ecosystem. Soil Science Society of America Journal, 66, 2002-2008.

Gregg JW, Jones CG, Dawson TE (2003) Urbanization effects on tree growth in the vicinity of New York City. Nature, 424, 183-187.

Gregorich EG, Carter MR, Angers DA et al. (1994) Towards a minimum data set to assess soil organic-matter quality in agricultural soils. Canadian Journal of Soil Science, 74, 367-385.

Grimm NB, Grove JM, Pickett STA et al. (2000) Integrated approaches to long-term studies of urban ecological systems. Bioscience, 50, 571-584.

Groffman PM, Law NL, Belt KT et al. (2004) Nitrogen fluxes and retention in urban watershed ecosystems. Ecosystems, 7, 393-403.

Hoberg P, Johannisson C, Hoberg M et al. (1995) Measurements and abundances of $15 \mathrm{~N}$ and $13 \mathrm{C}$ as tools in retrospective 
studies of $\mathrm{N}$ balances and water stress in forests: a discussion of preliminary results. Plant and Soil, 168, 125-133.

Holling CS, Gunderson L (2002) Resilience and adaptive cycles. In: Panarchy: Understanding transformations in human and natural systems, Vol. 25-62 (eds Gunderson L, Holling CS), pp. 25-62. Island Press, Washington, DC.

Hope D, Gries C, Zhu WX et al. (2003) Socioeconomics drive urban plant diversity. Proceedings of the National Academy of Sciences of the United States of America, 100, 8788-8792.

Hope D, Zhu W, Gries C et al. (in press) Spatial variations in soil inorganic nitrogen across an arid urban ecosystem. Urban Ecosystems.

Howard DM, Howard PJA, Howard DC (1995) A Markov model projection of soil organic-carbon stores following land-use changes. Journal of Environmental Management, 45, 287-302.

Huxman TE, Snyder KA, Tissue D et al. (2004) Precipitation pulses and carbon fluxes in semiarid and arid ecosystems. Oecologia, 141, 254-268.

Idso CD, Idso SB, Balling RC (1998) The urban $\mathrm{CO}_{2}$ dome of Phoenix, Arizona. Physical Geography, 19, 95-108.

Jenerette GD, Harlan SL, Brazel A et al. (in review) Spatial heterogeneity of an urban heat island. Landscape Ecology.

Jenerette GD, Wu J (2001) Analysis and simulation of landuse change in the central Arizona-Phoenix region. Landscape Ecology, 16, 611-626.

Katz RW (2002) Techniques for estimating uncertainty in climate change scenarios and impact studies. Climate Research, 20, 167-185.

Kaye JP, Burke IC, Mosier AR et al. (2004) Methane and nitrous oxide fluxes from urban soils to the atmosphere. Ecological Applications, 14, 975-981.

Kaye JP, McCulley RL, Burke IC (2005) Carbon fluxes, nitrogen cycling, and soil microbial communities in adjacent urban, native, and agricultural ecosystems. Global Change Biology, 11, $1-13$.

King A (1991) Translating models across scale in the landscape. In: Quantitative Methods in Landscape Ecology (eds Turner MG, Gardner RH), pp. 479-517. Springer-Verlag, New York, NY.

Lal R (1998) Soil erosion impact on agronomic productivity and environment quality. Critical Reviews in Plant Sciences, 17, 319-464.

Lewis DB, Kaye JP, Gries C et al. (2006) Agrarian legacy in soil nutrient pools of urbanizing arid lands. Global Change Biology, 12, 703-709.

Luck MA, Jenerette GD, Wu JG et al. (2001) The urban funnel model and the spatially heterogeneous ecological footprint. Ecosystems, 4, 782-796.

Luck MA, Wu J (2001) A gradient analysis of the landscape pattern of urbanization in the Phoenix metropolitan area of USA. Landscape Ecology, 17, 327-339.

Martin CA (2001) Landscape water use in Phoenix, Arizona. Desert Plants, 17, 26-31.

Massey DS (1996) The age of extremes: concentrated affluence and poverty in the twenty-first century. Demography, 33, 395-412.

McDonnell MJ, Pickett STA, Groffman P et al. (1997) Ecosystem processes along an urban-to-rural gradient. Urban Ecosystems, 1, 21-36.
Milne BT (1998) Motivation and benefits of complex systems approaches in ecology. Ecosystems, 1, 449-456.

Milne BT, Gupta VK, Restrepo C (2002) A scale invariant coupling of plants, water, energy, and terrain. Ecoscience, 9, 191-199.

Noy-Meir I (1973) Desert ecosystems: environmental and producers. Annual Review of Ecology and Systematics, 4, 25-51.

Oke TR (1973) City size and urban heat island. Atmospheric Environment, 7, 769-779.

O'Neill RV (1989) Perspectives in hierarchy and scale. In: Perspectives in Ecological Theory (eds Roughgarden J, May RM, Levin S), pp. 140-156. Princeton University Press, Princeton, NJ.

O’Neill RV, DeAngelis DL, Waide JB et al. (1986) A Hierarchical Concept of Ecosystems. Princeton University Press, Princeton, NJ.

Osmond B, Ananyev G, Berry J et al. (2004) Changing the way we think about global change research: scaling up in experimental ecosystem science. Global Change Biology, 10, 393-407.

Pavao-Zuckerman MA, Coleman DC (2005) Decomposition of chestnut oak (Quercus prinus) leaves and nitrogen mineralization in an urban environment. Biology and Fertility of Soils, 41, 343-349.

Peterjohn WT, Schlesinger WH (1990) Nitrogen loss from deserts in the Southwestern United-States. Biogeochemistry, 10, 67-79.

Peterson BJ, Fry B (1987) Stable isotopes in ecosystem studies. Annual Review of Ecology and Systematics, 18, 293-320.

Pickett STA, Cadenasso ML, Grove JM et al. (2001) Urban ecological systems: linking terrestrial ecological, physical, and socioeconomic components of metropolitan areas. Annual Review of Ecology and Systematics, 32, 127-157.

Post WM, Pastor J, Zinke PJ et al. (1985) Global patterns of soilnitrogen storage. Nature, 317, 613-616.

Potvin C, Roff DA (1993) Distribution-free and robust statisticalmethods: viable alternatives to parametric statistics. Ecology, 74, 1617-1628.

Pouyat R, Groffman P, Yesilonis I et al. (2002) Soil carbon pools and fluxes in urban ecosystems. Environmental Pollution, 116, S107-S118.

Pouyat RV, Carreiro MM (2003) Controls on mass loss and nitrogen dynamics of oak leaf litter along an urban-rural land-use gradient. Oecologia, 135, 288-298.

Pouyat RV, McDonnell MJ, Pickett STA (1995) Soil characteristics of oak stands along an urban-rural land-use gradient. Journal of Environmental Quality, 24, 516-526.

Pouyat RV, Parmelee RW, Carreiro MM (1994) Environmentaleffects of forest soil-invertebrate and fungal densities in oak stands along an urban-rural land-use gradient. Pedobiologia, 38, 385-399.

Rastetter EB, King AW, Cosby BJ et al. (1992) Aggregating sinescale ecological knowledge to model coarser-scale attributes of ecosystems. Ecological Applications, 2, 55-70.

Redman CL (1999) Human Impact on Ancient Environments. University of Arizona Press, Tucson.

Robertson GP, Crum JR, Ellis BG (1993) The spatial variability of soil resources following long-term disturbance. Oecologia, 96, 451-456.

Robertson GP, Klingensmith KM, Klug MJ et al. (1997) Soil resources, microbial activity, and primary production across an agricultural ecosystem. Ecological Applications, 7, 158-170. 
Schleuss U, Wu QL, Blume HP (1998) Variability of soils in urban and periurban areas in Northern Germany. Catena, 33, 255-270.

Schneider DC (2001) Spatial allometry: theory and application to experimental and natural aquatic ecosystems. In: Scaling Relations in Experimental Ecology (eds Gardner RH, Kemp WM, Kennedy VS, Peterson JE), pp. 113-153. Columbia University Press, New York, NY.

Stefanov WL, Ramsey MS, Christensen PR (2001) Monitoring urban land cover change: an expert system approach to land cover classification of semiarid to arid urban centers. Remote Sensing of Environment, 77, 173-185.

Tilman D, Lehman CL, Bristow CE (1998) Diversity-stability relationships: statistical inevitability or ecological consequence? American Naturalist, 151, 277-282.

Titus JH, Nowak RS, Smith SD (2002) Soil resource heterogeneity in the Mojave Desert. Journal of Arid Environments, 52, 269-292.

Turner DP, Ollinger S, Smith ML et al. (2004) Scaling net primary production to a MODIS footprint in support of earth observing system product validation. International Journal of Remote Sensing, 25, 1961-1979.

Turner RM, Brown DE (1994) Tropical-subtropical deserts. In: Biotic Communities: Southwestern United States and Northwestern Mexico (ed. Brown DE), pp. 180-223. University of Utah Press, Salt Lake City, UT.

United Nations Centre for Human Settlements (2001) Cities in a Globalizing World: Global Report on Human Settlements 2001. Earthscan Publications, London, UK.
Vitousek PM (1994) Beyond global warming: ecology and global change. Ecology, 75, 1861-1876.

Warren A, Sud YC, Rozanov B (1996) The future of deserts. Journal of Arid Environments, 32, 75-89.

Wessman CA (1992) Spatial scales and global change - bridging the gap from plots to gem grid cells. Annual Review of Ecology and Systematics, 23, 175-200.

West NE, Klemmedson JO (1978) Structural distribution of nitrogen in desert ecosystems. In: Nitrogen in Desert Ecosystems (eds West NE, Skujins J), pp. 1-16. Dowden, Hutchinson and Ross, Stroudsburg, PA.

Williams M, Rastetter EB, Shaver GR et al. (2001) Primary production of an arctic watershed: an uncertainty analysis. Ecological Applications, 11, 1800-1816.

Wu J (2004) Effects of changing scale on landscape pattern analysis: scaling relations. Landscape Ecology, 19, 125-138.

Wu J, Jones B, Li H (eds) (2005) Scaling and Uncertainty Analysis in Ecology: Methods and Applications. Springer, Dordrecht, the Netherlands.

Wu JG (1999) Hierarchy and scaling: extrapolating information along a scaling ladder. Canadian Journal of Remote Sensing, 25, 367-380.

Zhu WX, Carreiro MA (2004) Temporal and spatial variations in nitrogen transformations in deciduous forest ecosystems along an urban-rural gradient. Soil Biology and Biochemistry, $36,267-278$. 